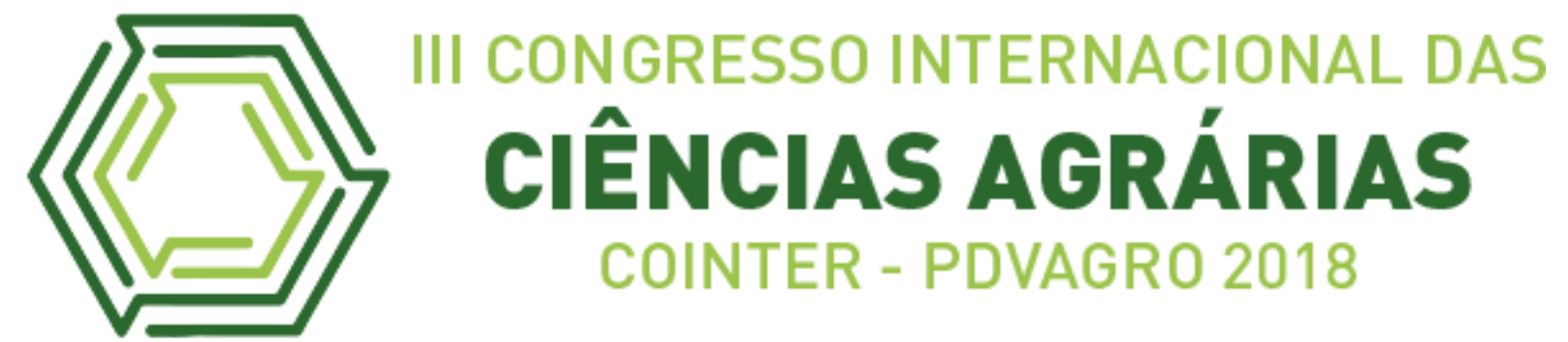

\title{
LEVANTAMENTO FITOSSOCIOLÓGICO DE PLANTAS DANINHAS EM CULTIVO DE MANDIOCA, NO MUNICÍPIO DE VITÓRIA DA CONQUISTA - BAHIA.
}

\section{PHYTOSOCIOLOGICAL SURVEY OF WEED IN CASSAVA CULTIVATION IN THE MUNICIPALITY OF VITÓRIA DA CONQUISTA - BAHIA}

Apresentação: Pôster

\begin{abstract}
Daniel Santos Freire ${ }^{1}$; Ramon Soares da Mata ${ }^{2}$; Geovana Brito Queiroz ${ }^{3}$; Thais Santana Soares ${ }^{4}$; Maurício Robério Silva Soares ${ }^{5}$
\end{abstract}

DOI: $\underline{\text { https://doi.org/10.31692/2526-7701.IIICOINTERPDVAGRO.2018.00562 }}$

\section{Introdução}

A mandioca (Manihot esculenta Crantz) é uma cultura de importância social e econômica cultivada em todas as regiões do Brasil. É utilizada como importante fonte de carboidrato na alimentação humana (SCHONS et al., 2009), sendo também é aproveitada na alimentação animal por meio dos seus subprodutos (ANDRÉ e DOS SANTOS, 2012). O Brasil se destaca por ser o segundo maior produtor de mandioca do mundo, produzindo mais de 20.606 toneladas, impulsionado pelos estados do Pará, Paraná e Bahia, que são os estados mais produtores (FERNANDES, 2018).

Nos sistemas de produção da mandioca e outros cultivos agrícolas, é comum a presença de plantas daninhas, que ocasionam redução na produtividade e na qualidade do produto final e onera o sistema produtivo (NICHOLS et al., 2015), uma vez que são capazes de adaptar aos mais variados tipos de limitações de crescimento e desenvolvimento (KARAM, 2007).

Uma das formas do manejo integrado das plantas daninhas é a realização do levantamento fitossociológico, o qual permite identificar e quantificar as espécies presentes nas áreas cultivadas, bem como definir a forma de manejo adequada para essas populações (OLIVEIRA; FREITAS, 2008).

O objetivo desse trabalho foi realizar um levantamento fitossociológico de plantas

\footnotetext{
${ }^{1}$ Graduando em Agronomia, Universidade Estadual do Sudoeste da Bahia - UESB, danielfreirester@gmail.com

${ }^{2}$ Graduando em Agronomia, Universidade Estadual do Sudoeste da Bahia - UESB, ramondamata@hotmail.com

${ }^{3}$ Graduando em Agronomia, Universidade Estadual do Sudoeste da Bahia - UESB, geovanabritoq@hotmail.com

${ }^{4}$ Graduando em Agronomia, Universidade Estadual do Sudoeste da Bahia - UESB, thaissspfc@gmail.com

${ }^{5}$ Doutor, Universidade Estadual do Sudoeste da Bahia - UESB, mauriciouesb@hotmail.com
} 
daninhas presentes em cultivo de mandioca no município de Vitória da Conquista - Bahia.

\section{Fundamentação Teórica}

O estado da Bahia se destaca como o terceiro produtor de mandioca nacional, entretanto, a produtividade do estado é inferior à produtividade média nacional, sendo 10,8 t/ha e 14,6 t/ha respectivamente (FERNANDES, 2018). Dentre as causas que contribuem para essa baixa produtividade, destaca-se a falta de cultivares adaptadas às diferentes condições de cultivo, a realização inadequada ou a falta de práticas culturais, emprego de materiais de plantio de baixa qualidade e a competição com plantas daninhas (CARDOSO et al., 2013).

As plantas daninhas interferem no crescimento e desenvolvimento dos cultivos de interesse econômico, pois necessitam dos mesmos fatores exigidos pela cultura, como água, luz, nutriente e espaço físico, estabelecendo uma relação competitiva em um mesmo local (VASCONCELOS; DA SILVA e LIMA, 2012).

A cultura da mandioca é muito suscetível à competição com as plantas daninhas, como consequência ocorrem perdas na produtividade de raízes de até 96\% (FONTES et al., 2014). Essa perda de rendimento da cultura da mandioca relaciona-se com o momento inadequado de controle, às condições ambientais nos locais de cultivo, as características da comunidade daninha, das variedades cultivadas, de seus sistemas de produção e o período de convivência (COSTA et al., 2013).

A identificação das espécies de plantas daninhas é fundamental, pois cada espécie apresenta um potencial de se estabelecer na área e sua competitividade pode interferir de forma diferenciada entre as culturas (CRUZ et al., 2009).

Por esse motivo, a realização do levantamento fitossociológico se constitui uma importante etapa no manejo de ervas daninha, pois, é uma ferramenta que permite identificar espécies, e, além disso, fazer várias inferências sobre a população, como a obtenção de dados de frequência, densidade, abundância e índice de importância relativa (ERASMO et al., 2004).

As informações coletadas a partir do levantamento fitossociológico, poderão ser utilizadas no manejo integrado de plantas daninhas, tendo a previsão da necessidade de controle, realização dos manejos de solo, da cultura e proporcionando uma utilização mais racional dos herbicidas, com base em considerações de custo/benefício na produção (VASCONCELOS, SILVA e LIMA, 2012). 


\section{Metodologia}

O estudo foi desenvolvido no Campo Experimental da Universidade Estadual do Sudoeste da Bahia (UESB), Campus Vitória da Conquista - Bahia em setembro de 2018. A localização geográfica a $14^{\circ} 51^{\prime}$ de Latitude Sul e 40 50 ' de Longitude Oeste, em altitude média de $941 \mathrm{~m}$.

O levantamento foi realizado em um plantio de mandioca (Manihot esculenta Crantz) variedade Sergipe com aproximadamente sete meses, em espaçamento 1,0 m x 1,0 m estabelecida em uma área de 0,3 hectares. Para a condução do estudo, foi utilizada uma armação metálica quadrada com área de $0,25 \mathrm{~m}^{2}$, a qual foi lançada 24 vezes, aleatoriamente no local de estudo, para obtenção das amostras.

As plantas daninhas situadas na área amostrada foram seccionadas rente ao solo e, em seguida, levadas ao Laboratório de Biotecnologia para identificação e quantificação das espécies. De acordo com a identificação das espécies, foi determinado os parâmetros fitossociológicos segundo Mueller-Dombois e Ellenberg (1974), sendo: a Frequência relativa $(\mathrm{FR})=($ frequência da espécie/frequência total das espécies) $\mathrm{x} 100$; Densidade relativa $(\mathrm{DR})=$ (densidade da espécie/densidade total das espécies) x 100; Abundância relativa (AR) = (abundância da espécie/abundância total das espécies) x 100; Índice de valor de importância $(\mathrm{IVI})=\mathrm{FR}+\mathrm{DR}+\mathrm{AR}$.

\section{Resultados e Discussões}

A comunidade de plantas daninhas encontrada_no levantamento fitossociológico foi composta por nove espécies, distribuídas em seis famílias: Amaranthaceae, Asteraceae, Malvaceae, Nyctaginaceae, Poaceae e Portulaceae (Tabela 1).

As espécies mais frequentes foram Bidens pilosa, Brachiaria plantaginea, Portulaca oleracea e Digitaria horizontalis. Essas espécies são comumente encontradas nas culturas de mandioca em outros estados, corroborando com os resultados encontrados por Biffe et al. (2010), Pinotti et al. (2010) e Albuquerque et al. (2014).

O Picão-preto (Bidens pilosa) foi encontrado em quase todas as amostras, justificando ser a espécie com maior frequência, densidade, abundância e índice de valor de importância. Essa daninha é considerada uma das plantas mais infestantes de culturas anuais e perenes (ADEGAS et al., 2003).

O Capim-colchão (Digitaria horizontalis) e a Beldroega (Portulaca oleracea) ficaram 
numericamente próximos quando comparadas entre os atributos avaliados. Essas espécies apresentaram índice de valor de importância, densidade relativa, abundância relativa superiores às demais espécies, com exceção do Picão-preto. Além disso, essas duas espécies foram iguais para densidade relativa, visto que apresentaram o mesmo número de indivíduos.

De acordo com Albuquerque et al., (2008) determinadas plantas daninhas ocorrentes na cultura da mandioca podem ser consideradas um problema localizado devido às particularidades de cada região, por esse motivo, parte das espécies encontradas no estudo, também foram encontradas por Maciel et al. (2010) na cultura do café, Cardoso et al. (2013) em cultivo de mandioca, Lima et al. (2017) em feijão caupi. Todos realizados no município de Vitória da Conquista - Bahia.

Tabela 1: Identificação, frequência relativa (FR), densidade relativa (DR), abundância relativa (AR) e índice de valor de importância (IVI) das espécies de plantas daninhas coletadas em cultivo da mandioca na área experimental da UESB em Vitória da Conquista, BA, 2018. Fonte:Própria

\begin{tabular}{ccccccc}
\hline Família & Espécies & Nome Comum & \%FR & \%DR & \%AR & \%IVI \\
\hline Amaranthaceae & Amaranthus hybridus & Caruru roxo & 2,82 & 0,26 & 1,78 & 4,85 \\
& Blainvillea latifolia & Picão grande & 7,04 & 1,79 & 4,97 & 13,80 \\
Asteraceae & Bidens pilosa & Picão preto & 26,76 & 62,96 & 46,10 & 135,82 \\
& Emilia sonchifolia & Falsa serralha & 8,45 & 2,04 & 4,74 & 15,23 \\
Malvaceae & Sida spinosa & Guanxuma & 1,41 & 0,13 & 1,78 & 3,31 \\
Nyctaginaceae & Boerhavia diffusa & Agarra pinto & 4,23 & 0,38 & 1,78 & 6,39 \\
Poaceae & Brachiaria plantaginea & Capim- & 16,90 & 8,68 & 10,07 & 35,65 \\
Portulaceae & Digitaria horizontalis & Capim-colchão & 15,49 & 11,88 & 15,02 & 42,39 \\
Total & Portulaca oleracea & Beldroega & 16,90 & 11,88 & 13,77 & 42,55 \\
& 9 & & 100 & 100 & 100 & 300 \\
\hline
\end{tabular}

\%FR: Frequência relativa; \%DR: Densidade relativa; \%AR: Abundância relativa; \%IVI: Índice de valor de importância.

\section{Conclusões}

Foram encontradas nove espécies de plantas daninhas, distribuída em seis famílias botânicas. A espécie Bidens pilosa apresentou predominância quando comparada às demais, seguida por Portulaca oleracea e Digitaria horizontalis respectivamente.

\section{Referências}

ADEGAS, F.S.; VOLL, E.; PRETE, C.E.C. Embebição e germinação de sementes de picãopreto (Bidens pilosa). Planta Daninha, v. 21, n. 1, p. 21-25, 2003.

ALBUQUERQUE, J.A.A.; EVANGELISTA, M.O.; MATES, A.P.K.; ALVES, J.M.A.; OLIVEIRA, N.T.; SEDIYAMA, T.; SILVA, A.A. Occurrence of weeds in cassava savanna plantations in Roraima. Planta Daninha, v. 32, n. 1, p. 91-98, 2014. 
ALBUQUERQUE, J.A.A.; SEDIYAMA, T.; SILVA, A.A.; CARNEIRO, J.E.S.; CECON, P.R.; ALVES, J.M.A. Interferência de plantas daninhas sobre a produtividade da mandioca (Manihot esculenta) Weed interference in cassava (Manihot esculenta) yield. Planta Daninha, v. 26, n. 2, p. 279-289, 2008.

ANDRÉ, T.B.; DOS SANTOS, A.C. Uso de produtos da cultura da mandioca (Manihot) na produção animal. Enciclopédia Biosfera, Centro Científico Conhecer, Goiânia, v.8, n.15; p.1622, 2012.

BIFFE, D.F.; CONSTANTIN, J.; OLIVEIRA JR, R.S.; FRANCHINI, L.H.M.; RIOS, F.A.; BLAINSKI, E.; CAVALIERI, S.D. Período de interferência de plantas daninhas em mandioca (Manihot esculenta) no noroeste do Paraná. Planta Daninha, p. 471-478, 2010.

CARDOSO, A.D; VIANA, A.E.S.; BARBOSA, R.P.; TEIXEIRA, P.R.G.; CARDOSO JÚNIOR, N.S.; FOGAÇA, J.J.N.L.; Levantamento fitossociológico de plantas daninhas na cultura da mandioca em Vitória da Conquista, Bahia. Bioscience Journal, v. 29, n. 5, 2013.

COSTA, N.V.; RITTER, L.; PERES, E.J.L.; SILVA, P;V.;VASCONCELOS, E.S. Weed interference periods in the 'Fécula Branca'cassava. Planta Daninha, v. 31, n. 3, p. 533-542, 2013.

CRUZ, D. L. S. Levantamento de plantas daninhas em área rotacionada com as culturas da soja, milho e arroz irrigado no cerrado de Roraima. Nota Técnica. v. 3, n. 1, p. 58-63, 2009.

DE GOES MACIEL, C.D.; POLETINE, J.P.; DE OLIVEIRA NETO, A.M.; GUERRA, N.; JUSTINIANO,W. Levantamento fitossociológico de plantas daninhas em cafezal orgânico. Bragantia, Campinas, v.69, n.3, p. 631-636, 2010.

ERASMO, E.A.L.; AZEVEDO, W.R.; SARMENTO, R.A.; CUNHA, A.M.; GARCIA, S.L.R. Potencial de espécies utilizadas como adubo verde no manejo integrado de plantas daninhas. Planta Daninha, v.22, p.337-342, 2004.

FERNANDES, G.L.C. Mandioca em números. Disponível em: <https://www.embrapa.br/congresso-de-mandioca-2018/mandioca-em-numeros>.

FONTES, J.; OLIVEIRA, I.J.; PEDROZO, C.; ROCHA, R.N.C.; MORAIS, R.R.;MUNIZ, A. Períodos de interferência de plantas daninhas na cultura da macaxeira, variedade Aipim-Manteiga, em terra firme do Amazonas. Embrapa Amazônia Ocidental-Circular Técnica (INFOTECA-E), 2014.

KARAM, D. Manejo integrado de plantas daninhas. In: Embrapa Milho e Sorgo-Artigo em anais de congresso,Anais... Mossoró: UFERSA, 2007.

LIMA, R. S.; SÃO JOSÉ, A.R.; SOARES, M.R.S.; MOREIRA, E.S.; NETO, A.C.A.; CARDOSO, A.D.; MORAIS, O.M. Levantamento fitossociológico de plantas daninhas na cultura do feijão-caupi no município de Vitória da Conquista-BA. Magistra, v. 28, n. 3/4, p. 390-402, 2017. 
LOPES, A.D.; VIANA, E.S.; MATSOMOTO, S.N.; CARDOSO JÚNIOR, N.A.; SÃO JOSÉ, A.R.; Complementação da irrigação e épocas de colheita de mandioca cv. coqueiro no Planalto de Conquista, BA. Ciência agrotecnologia, Lavras, v. 34, n. 3, p. 579-587, 2010.

MUELLER-DOMBOIS, D.; ELLEMBERG, H. Aims and Methods of Vegetation Ecology. New York: J. Wiley. 347 p. 1974.

NICHOLS, V.; VERHULST, N.; COX, R.; GOVAERTS, B. Weed dynamics and conservation agriculture principles: a review. Field Crops Research, v. 183, p. 56-68,2015.

OLIVEIRA, A. R.; FREITAS, S. P. Levantamento fitossociológico de plantas daninhas em áreas de produção de cana-de-açúcar. Planta Daninha, Viçosa, v. 26, n. 1, 2008.

PINOTTI, E.B.; BICUDO, S.J.; CURCELLI, F.; DE SOUZA DOURADO, W. Levantamento florístico de plantas daninhas na cultura da mandioca no município de Pompéia-SP. Revista Raízes e Amidos Tropicais, v. 6, n. 1, p. 120-125, 2010.

SCHONS, A.; STRECK, N.A.; STORCK, L.; BURIOL, G.A.; ZANON, A.J.; PINHEIRO, D.G.; KRAULICH, B. Arranjos de plantas de mandioca e milho em cultivo solteiro e consorciado: crescimento, desenvolvimento e produtividade. Bragantia, v.68, p.155-167, 2009.

VASCONCELOS, A.F.A.; DA SILVA, A.F.A.; LIMA, R.S. Interferência de plantas daninhas sobre plantas cultivadas. Agropecuária científica no semiárido, v. 8, n. 1, p. 01-06, 2012. 